\title{
Female and male Blue Tits (Cyanistes caeruleus) sing in response to experimental predator exposition
}

\author{
Katharina Mahr $^{1} \cdot$ Carlo L. Seifert $^{2} \cdot$ Herbert Hoi $^{1}$
}

Received: 28 January 2016/Revised: 17 March 2016/Accepted: 7 April 2016/Published online: 18 April 2016

(c) The Author(s) 2016. This article is published with open access at Springerlink.com

\begin{abstract}
Female song is recognized to serve a similar function as male song and underlies sexual selection processes; yet certain patterns of the expression of female singing behaviour are not in line with traditional explanations known from male songbirds. In particular, in northern hemisphere songbirds, female singing behaviour is regarded to occur only rarely, and; therefore, studies investigating it are sparse. Within the framework of an experimental study on nest defence behaviour, we observed female singing in a common European passerine, namely, the Blue Tit (Cyanistes caeruleus). Females expressed singing behaviour when a dummy of a Sparrow Hawk was exposed to the nest, raising the idea that song might be multifunctional in this species.
\end{abstract}

Keywords Defence behaviour - Female song ·

Passerines $\cdot$ Predation $\cdot$ Sexual selection

Communicated by M. Naguib.

Electronic supplementary material The online version of this article (doi:10.1007/s10336-016-1345-3) contains supplementary material, which is available to authorized users.

Katharina Mahr

Katharina.Mahr@vetmeduni.ac.at

1 Department of Integrative Biology and Evolution, Konrad Lorenz Institute of Ethology, University of Veterinary Medicine, Savoyenstraße 1a, 1160 Vienna, Austria

2 Faculty of Science, The Czech Academy of Sciences, University of South Bohemia and Biology Center, Branišovská 31, 37005 České Budějovice, Czech Republic

\section{Zusammenfassung}

Gesangsverhalten von weiblichen und männlichen Blaumeisen (Cyanistes caeruleus) bei Prädationsexperimenten

Es wird allgemein angenommen, dass die Funktionen von Weibchengesängen denen der Männchen sehr ähnlich sind und sie primär dem Territorial- und Partnerwahlverhalten (intra- und intersexuelle Selektion) dienen. Männchen und Weibchen unterscheiden sich aber aufgrund ihrer Physiologie und auch ihrer Reproduktionskosten. Man würde daher erwarten, dass vor allem Weibchen, ihre Gesänge vielseitiger einsetzen. Besonders bei Singvögeln der nördlichen Hemisphäre wurde weiblicher Gesang bis heute nur selten dokumentiert. Im Rahmen einer experimentellen Studie beschreibt die vorliegende Arbeit erstmals das Auftreten weiblichen Gesanges bei Blaumeisen (Cyanistes caeruleus) in der Gegenwart einer Sperberattrappe. Diese Beobachtung unterstützt die Hypothese, dass Weibchengesänge in mehreren und auch anderen als den hauptsächlich erwähnten und von Männchen bekannten Funktionen eingesetzt werden können.

The expression of songs is regarded to be typical for male songbirds and has been the centre of numerous investigations over the last centuries (Gil and Gahr 2002). Only in recent decades, an increasing number of studies has revealed that female songbirds are not a mute sex and that female singing behaviour is more common than originally thought (Langmore 1998; Riebel et al. 2005; Garamszegi et al. 2007; Odom et al. 2014). Female song has mainly been found in duetting species of the tropics and subtropics (Langmore 1998; Garamszegi et al. 2007; Odom et al. 
2014), whereas in the northern hemisphere, female songbirds seem to sing only rarely and under certain circumstances. Garamszegi et al. (2007) revealed in fact in a systematic study that in European passerines female singing behaviour does occur in a number of species.

Sexual selection is considered to be the major driving force behind the continued existence of female singing behaviour, including inter- and intrasexual selection processes (Gil and Gahr 2002; Nowicki and Searcy 2004). Considering that most of our knowledge about song in passerines is due to intense research on singing behaviour in males, the interpretation of female behavioural patterns might possibly be biased. Nevertheless, an increasing number of studies is trying to find alternative explanations for female singing behaviour. This reveals that song functions in a variety of contexts not commonly known from male songbirds, e.g., in the display of pair cohesion and commitment, or in family coordination (de Silva et al. 2004; Hall and Peters 2008).

Another unusual behaviour that has been observed in males of some species is the expression of song in the presence of predators (Langmore and Mulder 1992; Cresswell 1994; Zelano et al. 2001). Whereas alarm-vocalizations are well studied in both sexes, to our knowledge this behaviour has yet not been observed in female passerines. Our study, therefore, focused on the description of context-dependent singing behaviour of Blue Tits (Cyanistes caeruleus) via an experiment on vocalization patterns during predation events.

We recorded the response of female Blue Tits towards two predator types, which are commonly found in the study area [nest-box population in the Viennese forests near Vienna; $48^{\circ} 18^{\prime} \mathrm{N}, 16^{\circ} 08^{\prime} \mathrm{E}$; about $320 \mathrm{~m}$ a.s.l. (Mahr et al. 2012, 2015)]. Predation events were simulated by presenting: (1) a stuffed model of a Sparrow Hawk (Accipiter nisus) $(N=10)$, which represents a common aerial raptor frequently preying on adult and young, and (2) a dummy of an Aesculapian Snake (Zamenis longissimus) $(N=10)$, which is considered to be a threat to nestlings but not to adults (Mahr et al. 2012, 2015). For individual recognition, the adult birds were sexed based on the presence of a brood patch and banded with a standard aluminium ring and a unique combination of darvic colour-rings.

We sampled each nest twice, on day $11( \pm 1)$ posthatching and 1 day later, and recorded vocalization behaviour during trials simulating predation risk. Therefore, a stuffed Sparrow Hawk or a Rubber Snake was exposed on a branch in the vicinity to the nest box of the target individuals (Snake: $0.5 \mathrm{~m}$, Sparrow Hawk: app. $1.5 \mathrm{~m}$ ); the predator type was altered randomly. In total, we recorded the response of ten Blue Tits. Female vocalization patterns were recorded from a distance of 5-15 $\mathrm{m}$ using a parabolic microphone (Telinga Microphones, Sweden), connected to a portable TASCAM DR-44WL digital audio recorder (TASCAM, US). All sound files were recorded as broadcast wave files (24 bit $48 \mathrm{k} \mathrm{Hz}$ ) and edited with Audacity 1.2.6 (free digital audio editor, D. Mazzoni and R. Dannenberg, 2006). The sonograms represented in Figs. 1 and 2 were created on the Hann algorithm display type (filter bandwidth $124 \mathrm{~Hz}$, size 512 samples, time grid overlap $50 \%$, grid resolution $5.8 \mathrm{~ms}, 86.1 \mathrm{~Hz}$, DTF 512 samples) using RAVEN 1.4. For the sonograms see Electronic Supplementary Material.

We analysed the first $3 \mathrm{~min}$ of each recording and our observations revealed that in ten trials, singing behaviour occurred during six challenges. In all six cases, singing behaviour was a reaction towards the Sparrow Hawk, and out of six observations this behaviour could be clearly assigned to females three times, to males two times, and twice no further identification of individuals was possible (Table 1). In two observations, the territorial male was present, whereas during one trial the partner was absent. In contrast, no singing behaviour of either sex was observed as a response during challenge trials involving the Aesculapian Snake.

Female Blue Tits display a variety of vocalization patterns, playing a major role in pair communication (Gorissen and Eens 2005). This also partly applies to the singing behaviour of female Blue Tits, which was described previously by Hinde (1952) and occurs during aggressive encounters with other females, but was also observed when a territorial male courted other females.

Our observations indicate that Blue Tit female singing behaviour occurs in the context of high predation risk. This is supported by the finding that we did not observe singing behaviour in either males or females during predation trials conducted with an Aesculapian Snake, which poses only a minimum risk to defending adults. This might indicate that female song also serves in other functions than sexual selection and territorial behaviour. The song observed in females very much resembles that of males (see Figs. 1, 2).

The display of singing behaviour in the presence of predators has been observed in male Blue Tits and other male passerines (Langmore and Mulder 1992; Cresswell 1994; Zelano et al. 2001). The question arises as to why birds detecting an aerial raptor produce a conspicuous signal exposing them to a potential risk. One suggestion is that song might be directed towards the predator. Male Skylarks (Alauda arvensis), for example, sing in the presence of aerial raptors and use song as pursuit-deterrent signal (Cresswell 1994). A similar phenomenon was previously observed in a study of Laiolo et al. (2004), which indicated that alarm vocalizations can be condition-dependent and might, therefore, function as signals for predators to estimate the ability of a prey to escape. 

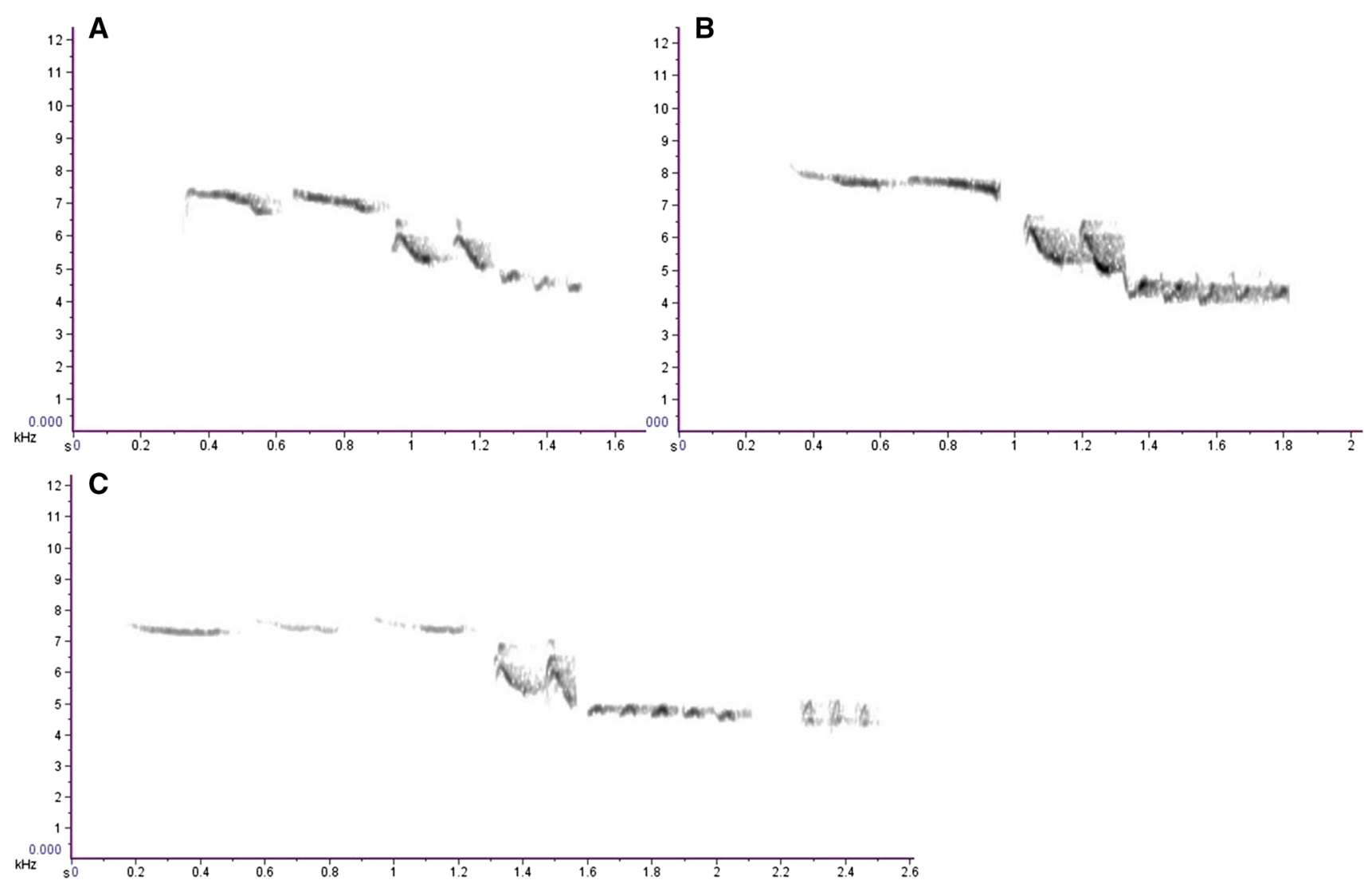

Fig. 1 Sonograms of three female Blue Tits recorded during the simulation of a predation event

Fig. 2 Sonograms of a male Blue Tit recorded during the simulation of a predation event

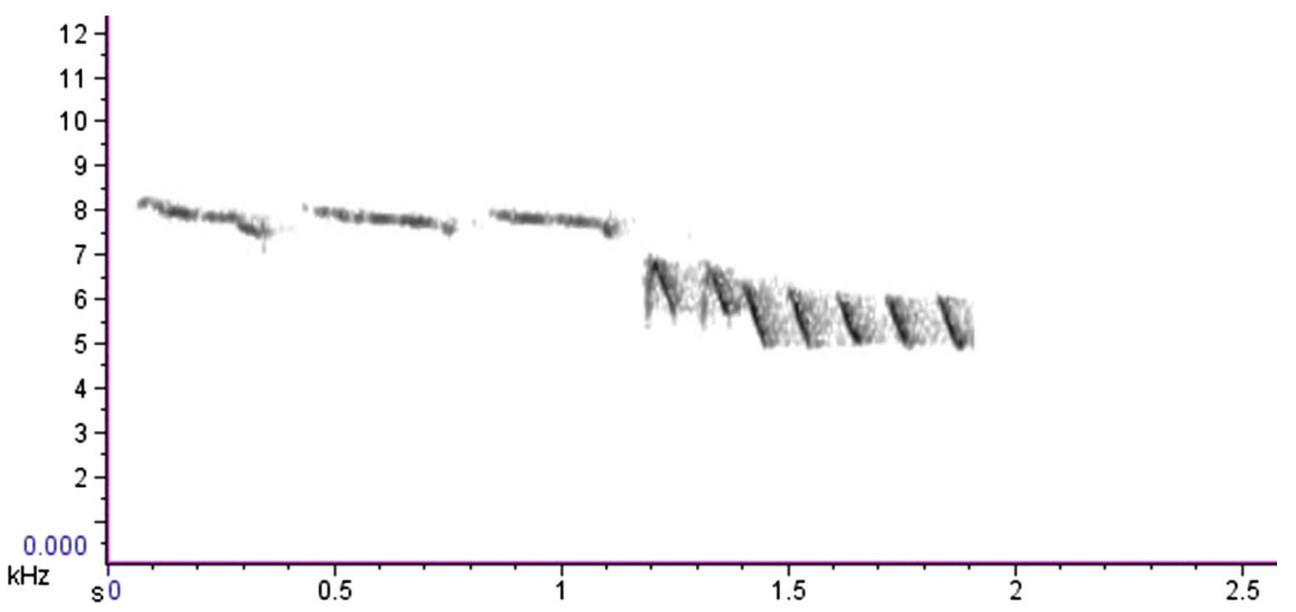

The display of singing behaviour in the presence of a predator has also been demonstrated in two species of the Maluridae, but the function of those songs remains unclear. They are suggested to attract potential mating partners for extra-pair copulations, but no relationship between reproductive success and song display in predator presence was found so far (Langmore and Mulder 1992; Zelano et al. 2001). However, in regard to our observation in blue tits, it seems less likely that females or males use song as a long distance signal to attract mating partners for extra-pair copulations. This applies particularly to female song, since the experiments were conducted when the nestlings were relatively old and female reproductive capacities might be limited. Long-term monitoring of our study population has revealed that blue tits produce only one brood per year and that replacement clutches are also rare. Moreover, the birds breed synchronously, and the availability of mating partners might be limited. 
Table 1 Singing behaviour occurred in 6 out of 10 predation trials using a stuffed model of a Sparrow Hawk

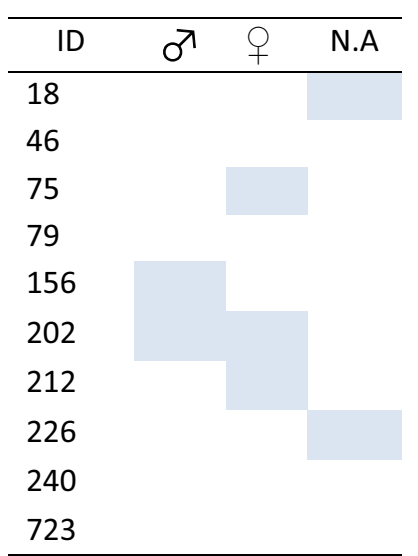

Female song was observed 3 times, male song 2 times, and twice no further identification of individuals was possible (singing events are marked as grey squares)

Hinde (1952) suggested that in addition to its function in mate attraction and territoriality, song in male Blue Tits also occurs when the pair becomes separated during the pre-nesting period. This raises the question whether females also sing to retain their partners in the vicinity to the breeding site. In particular in a risky situation, females might gain benefits by calling their mate for support in defence. Since in two out of three observations, the partner of the singing female was present, this explanation seems less likely. On the other hand, singing behaviour was also observed in males, raising the question whether both sexes sing to stimulate pair cohesion in particular during situations where defence as a unit against a threat is required.

Alternatively, singing behaviour could be simply explained by a physiological mechanism. The presence of a Sparrow Hawk might represent a very stressful situation, triggering song through endocrinological mechanisms. However, further investigations would be required to draw firm conclusions about female singing behaviour during predation events in Blue Tits. Nevertheless, our data raise a number of questions regarding the interpretation of singing behaviour in female passerines in general and adds interesting aspects to the still sparse knowledge of the function of female song in songbirds.

Acknowledgments Open access funding provided by University of Veterinary Medicine Vienna. Sincere thanks are given to Renate Hengsberger, Bernhard Paces, and the teachers of the Sacré Coeur Pressbaum, in particular Margarethe Mahr for their support and assistance. We kindly thank the anonymous referee for valuable comments on the manuscript, as well as Prof. Hans-Christoph Winkler for discussions on the topic. All animal procedures were approved by the institutional ethics committee and the national authority according to $\$ 26$ of Law for Animal Experiments, Tierversuchsgesetz 2012-TG 2012 (reference no.: 68.205/0067-WF/ $\mathrm{II} / 3 \mathrm{~b} / 2014)$.

\section{Compliance with ethical standards}

Conflict of interest The authors declare no competing financial interests.

Open Access This article is distributed under the terms of the Creative Commons Attribution 4.0 International License (http://crea tivecommons.org/licenses/by/4.0/), which permits unrestricted use, distribution, and reproduction in any medium, provided you give appropriate credit to the original author(s) and the source, provide a link to the Creative Commons license, and indicate if changes were made.

\section{References}

Cresswell W (1994) Song as a pursuit-deterrent signal, and its occurrence relative to other anti-predation behaviours of skylark (Alauda arvensis) on attack by merlins (Falco columbarius). Behav Ecol Sociobiol 34:217-223. doi:10.1007/bf00167747

de Silva HG, Marantz CA, Pérez-Villafaña M (2004) Song in female Hylorchilus wrens. Wilson Bull 116:186-188. doi:10.1676/03126

Garamszegi LZ, Pavlova DZ, Eens M, Møller AP (2007) The evolution of song in female birds in Europe. Behav Ecol 18:86-96. doi:10.1093/beheco/ar1047

Gil D, Gahr M (2002) The honesty of bird song: multiple constraints for multiple traits. Trends Ecol Evol 17:133-141. doi:10.1016/ S0169-5347(02)02410-2

Gorissen L, Eens M (2005) Complex female vocal behaviour of great and blue tits inside the nesting cavity. Behaviour 142:489-506. doi:10.1163/1568539054012056

Hall ML, Peters A (2008) Coordination between the sexes for territorial defence in a duetting fairy-wren. Anim Behav 76:65-73. doi:10.1016/j.anbehav.2008.01.010

Hinde RA (1952) The behaviour of the great tit (Parus major) and some other related species. Behaviour Suppl 2:III, V-X, 1-201. http://www.jstor.org/stable/30039125

Laiolo P, Tella JL, Carrete M, Serrano D, López G (2004) Distress calls may honestly signal bird quality to predators. Proc R Soc Lond B 271:S513-S515. doi:10.1098/rsb1.2004.0239

Langmore NE (1998) Functions of duet and solo songs of female birds. Trends Ecol Evol 13:136-140. doi:10.1016/S01695347(97)01241-X

Langmore NE, Mulder RA (1992) A novel context for bird song: predator calls prompt male singing in the Kleptogamous Superb Fairy-Wren, Malurus cyaneus. Ethology 90:143-153. doi:10. 1111/j.1439-0310.1992.tb00828.x

Mahr K, Griggio M, Granatiero M, Hoi H (2012) Female attractiveness affects paternal investment: experimental evidence for male differential allocation in blue tits. Front Zool 9:14. doi:10.1186/ 1742-9994-9-14

Mahr K, Riegler G, Hoi H (2015) Parental risk management in relation to offspring defence: bad news for kids. Proc R Soc Lond B 282:20141670. doi:10.1098/rspb.2014.1670

Nowicki S, Searcy WA (2004) Song function and the evolution of female preferences. Why birds sing, why brains matter. Ann NY Acad Sci 1016:704-723. doi:10.1196/annals.1298.012 
Odom KJ, Hall ML, Riebel K, Omland KE, Langmore NE (2014) Female song is widespread and ancestral in songbirds. Nat Commun 5:3379. doi:10.1038/ncomms4379

Riebel K, Hall ML, Langmore NE (2005) Female songbirds still struggling to be heard. Trends Ecol Evol 20:419-420. doi:10. $1016 /$ j.tree.2005.04.024
Zelano B, Tarvin KA, Pruett-Jones S (2001) Singing in the face of danger: the anomalous type II vocalization of the splendid fairywren. Ethology 107:201-216. doi:10.1046/j.1439-0310.2001. 00645.x 